\title{
Teacher Related Causes of Boredom
}

\author{
Florence Uchechukwuka Nkwogu ${ }^{1} \quad$ Josephine Nonye Ubah $^{2 *}$ \\ 1.Department of Ophthalmology, College of Medicine, Imo State University, Orlu, Imo State, Nigeria \\ 2.Department of Ophthalmology, College of Health Sciences, Ladoke Akintola University Of Technology, PMB \\ 4400, Osogbo, Osun State, Nigeria
}

\section{The research is financed by the authors}

\section{Abstract}

Boredom is a well known phenomenon among students. It has different causes including teacher related ones. Boredom impacts negatively on students. The aim of the study was to find out the students perspective on teacher related causes of boredom. Semi structured questionnaire was distributed to a group of clinical medical students who were receiving lectures. There were different options on possible attitudes of the teachers that caused boredom during their lectures. Data analysis was done using SPSS version 21. There were 188 students who were recruited for the study. There was no statistical difference between male and female responses. All the options were highlighted by majority of students but prolonged lectures was the commonest identified cause of boredom. This was significantly affected by age $(p=0.002)$. Teachers need to be aware that they contribute to boredom in the class and also understand how this happens because boredom impacts negatively on learning.

Keywords: Boredom, causes, teacher related, students

DOI: $10.7176 / \mathrm{JEP} / 10-3-03$

\section{Introduction}

Boredom has been described as a legitimate emotion that is associated with learning and creativity (Belton \& Priyadharshini 2007). It is a common phenomenon among students (Mann 2007) and results from lack of interest or satisfaction in an activity leading to limited attention span (Giorgi 2016). When students get bored, they lose concentration and their minds drift. Boredom impacts negatively on learning (Nett et al. 2010). It could lead to school dropout and poor performance in school (Bearden et al. 1989). Almost $60 \%$ of the students found their lectures very boring (Mann 2007). Larson \& Richard (1991) reported boredom in about 32\% of students. Boredom could result from external factors (Kanevsky 2003) or personal dispositions (Larson \& Richards 1991), or both external and internal factors (Fisher 1988). The external causes could be lecturer or teacher, institutional or subject related (Ubah 2018).

Lecturers need to acquaint themselves with the different ways they could contribute to boredom, and the impact on their students' learning. These factors could be avoided to produce a more fruitful teaching-learning experience.

Some of the things teachers do that cause boredom were described by Linsin (2012) and included: teachers making students to sit for too long, talking for too long, making presentations complex rather than simplified, making topics that are interesting to be uninteresting, failing to adjust when it becomes obvious that students are losing concentration. Others are caused by teachers not incorporating diversity and fun during interaction with little challenge to the students.

The aim of the present study was to find out the ways teachers contributed to boredom from the students' perspective.

\section{Methods}

\subsection{Data collection}

A semi structured questionnaire was administered to students of a higher institution from levels 4 to 6 , on teacher related causes of boredom. They were to indicate the extent to which the options got them bored. The options incorporated in the questionnaire were, a) the manner the lecturer expresses himself while teaching, b) lecturer reading from written text, c) prolonged lectures, d) organising lectures towards the end of the day, e) series of lectures without break and f) lectures full of written texts without pictures and drawings. For each option, they were to indicate if they strongly agreed, agreed, not sure, disagreed and strongly disagreed. At the end, they were told to expatiate on the manners of the teacher's expression that made the situation worse. Other information obtained were age and sex. The candidates selected for the study were those who opted to fill the questionnaires and returned completely filled questionnaires.

\subsection{Data Analysis}

Data obtained was imputed into the computer and analysed using Statistical Package for Social Sciences Version 21. Expressions were in simple proportions, while bivariate analysis was carried using chi square. Statistical significance was set at $\mathrm{P}$ values of less than 0.05 . 


\section{Results}

There were 188 medical students in their semi-final and final years of study who submitted completed questionnaires that were included in the study.

Their ages ranged from 23 to 40 years of age, with modal age of 27 years. Figure 1.

There were 95 males and 93 females.

There was no statistical significance between male and female responses.

A good number of the students agreed that all the options given contributed to boredom with prolonged lectures being the most responsible, while the least was reading from written texts.

Only boredom from prolonged lectures was significantly affected by age. (Pearson Chi-Square 75.293, df 44, $\mathrm{p}=0.002$ ). Table 2 . The older respondents disagreed more with this cause of boredom compared to the younger ones.

\section{Discussion}

This study has highlighted certain characteristics of teachers that got students bored. As reported above, more than half of the class agreed that all the options contributed but prolonged lecture was very prominent and statistically significant, $p=0.002$. This was one of the 8 actions of teachers identified by Mann (2009) that caused boredom among students. It was also one of the predictors of boredom narrated by Daschmann et al (2014). During prolonged lectures, teachers talk for too long and also make learners sit for so long. The reason for prolonged lectures could either be that the time allotted to the lectures is rather short or that the teachers intentionally pile up the lectures to soothe their purposes.

Organising lectures towards the end of the day was the second commonest cause. At this time of the day, both students and lecturers are likely tired. This leads to decrease in ability to pay attention, and poor retention. The students easily get distracted as a result. When people are tired, they assimilate little and are not at their best. Learning is best in the mornings especially after a very good night's sleep (Buff 2013).

Organising lectures towards the end of the day was closely followed by lectures full of written texts without pictures and illustrations. Manner of expression by the teacher at lectures was also very prominent. The students went further to explain the teacher mannerisms that mostly got them distracted. These were: not being audible, not introducing any form of fun, not asking questions, not student friendly, being aggressive, proud, stingy with materials, having poor command of English language and rushing through lectures. Some lecturers were seen to look very angry, thereby instilling fear in the students. Those who were proud boasted about their qualifications, spoke to students without respect and even insulted them in some instances. Some lecturers either used medical terms that students did not understand or refused to answer questions. They would rather tell the students to look up the answers themselves. Daschmann et al (2014) further observed that teachers hardly realised that they could be antecedents of boredom.

Most lecturers engage in teaching through lectures. This rarely gives room for teacher / student interaction and so it is likely to cause boredom. Teachers employ this method to transmit information because many students are reached at a time. Many factors can cause boredom among learners; one of them is teacher oriented. Apart from the teachers having a knowledge of how they contribute to boredom in the class, and trying to avoid or minimise them, they also need to introduce methods of teaching that will eliminate boredom. One of these is applying different learning styles (Ubah 2012). Students learn by different methods which include: visual, auditory, read and write and kinesthetic methods. When students are engaged in cherished activities, their interest and enthusiasm will likely be aroused and they are less likely to be bored.

Teachers need to be aware that they could be the cause of boredom to students while teaching. They also need to know how this comes about. Boredom has to be eliminated or reduced to the barest minimum because it has a negative impact on learning and those who impact learning should not be the cause.

\section{Conclusion}

Teaching-learning experience is an indispensable aspect of education required for a change of attitude in the learner and subsequent ability to contribute to the society in which the individual finds himself. Boredom is an indispensable aspect of classroom learning as well. It has been established that teachers, whose duty is to impact knowledge to students also contribute to boredom in the class. Boredom has a negative impact on learning. Teachers need to go extra mile to understand that students could be bored and they could be contributors to boredom. They also need to be familiar with the ways they contribute to this and make conscious effort to minimise or eliminate it.

\section{References}

Bearden L.J., Spencer W.A., Moracco J.C. (1989), “A Study of High School dropouts”, School Counselor, 37(2):113-120.

Belton T., Priyadharshini E. (2007), "Boredom and schooling: A cross-disciplinary exploration”, Cambridge 
Journal of Education, 37(4):579-595.

Buff T. (2013), "The impact of Tiredness and Fatigue on Learning", [Online] Available: https://elearningindustry.com, (June 2, 2018).

Daschmann E.C., Goetz T. and Stupnisky R.H. (2014), "Exploring the antecedents of boredom: Do teachers know why students are bored?", Teaching and Teacher Education, 39:22-30.

Fisher C.D. (1998), "Effects of external and internal interruptions on boredom at work: Two studies", Journal of Organisational behavior, 19(5): 503-522.

Giorgi A.Z. (2016), "Boredom", Available www.healthline.com Viewed (November 1 $1^{\text {st }}, 2018$ ).

Kanevsky L., (2003), "To produce or not to produce? Understanding boredom and the honor in underachievement", Roeper Review 26(1):20-28.

Larson R.W. and Richards M.H. (1991), "Boredom in the middle school years: Blaming schools versus blaming students", American Journal of Education, 99(4):418-443.

Linsin M. (2012), "8 things that teachers do to cause boredom", [Online] Available: https://www.smartclassroommanagement.com, (June 4, 2018).

Mann S. (2009), "Why do 60\% of students find their lectures boring?", The guardian news, Available www.theguardian.com (May 31, 2017).

Nett U.E., Goetz T., Daniels L.M. (2010), "What to do wen feeling bored?: Students strategies for coping with boredom", Learning and Individual Differences, 20(6): 626-638.

Ubah J.N. (2018), "Predictors of boredom at lectures: Medical Students' experience", Advances in Social Sciences Research Journal, 5(1):91-95.

Ubah J.N. (2012), "Learning styles among medical students, a case study of Ladoke Akintola University of Technology Medical School; Osogbo, Western Nigeria”, Journal of Education and Practice, 3(5):47-49.

Table 1. Frequencies of response to different options.

\begin{tabular}{|l|l|l|l|l|}
\hline & $\begin{array}{l}\text { Agree } \\
\mathrm{n}=188\end{array}$ & $\begin{array}{l}\text { Not sure } \\
\mathrm{n}=188\end{array}$ & $\begin{array}{l}\text { Disagree } \\
\mathrm{n}=188\end{array}$ & Total \\
\hline Manner lecturer expresses himself while teaching & $121(64.3 \%)$ & $31(16.5 \%)$ & $36(19.2 \%)$ & $188(100 \%)$ \\
\hline Lecturer reading from written text & $116(61.7 \%)$ & $27(14.4 \%)$ & $45(13.9 \%)$ & $188(100 \%)$ \\
\hline Prolonged lectures & $171(90.9 \%)$ & $5(2.7 \%)$ & $12(6.4 \%)$ & $188(100 \%)$ \\
\hline Organising lectures towards end of the day & $166(88.3 \%)$ & $10(5.3 \%)$ & $12(6.4 \%)$ & $188(100 \%)$ \\
\hline Series of lectures without break & $130(69.1 \%)$ & $36(19.1 \%)$ & $22(11.7 \%)$ & $188(100 \%)$ \\
\hline $\begin{array}{l}\text { Lectures full of written texts without pictures and } \\
\text { illustrations }\end{array}$ & $162(86.1 \%)$ & $14(7.4 \%)$ & $12(6.4 \%)$ & $188(100 \%)$ \\
\hline
\end{tabular}

Table 2. Effect of age on teacher related responses to causes of boredom

\begin{tabular}{|l|l|l|l|}
\hline Option & Pearson Chi-Square & Df & P value \\
\hline Manner lecturer expresses himself & 34.862 & 44 & .836 \\
\hline Series of lectures without break & 54.755 & 44 & .149 \\
\hline Lectures full of written texts without pictures and illustrations & 38.940 & 44 & .688 \\
\hline Prolonged lectures & 75.293 & 44 & .002 \\
\hline Lectures towards the end of the day & 43.317 & 44 & .501 \\
\hline Lecturer reading from text & 51.955 & 44 & .192 \\
\hline
\end{tabular}




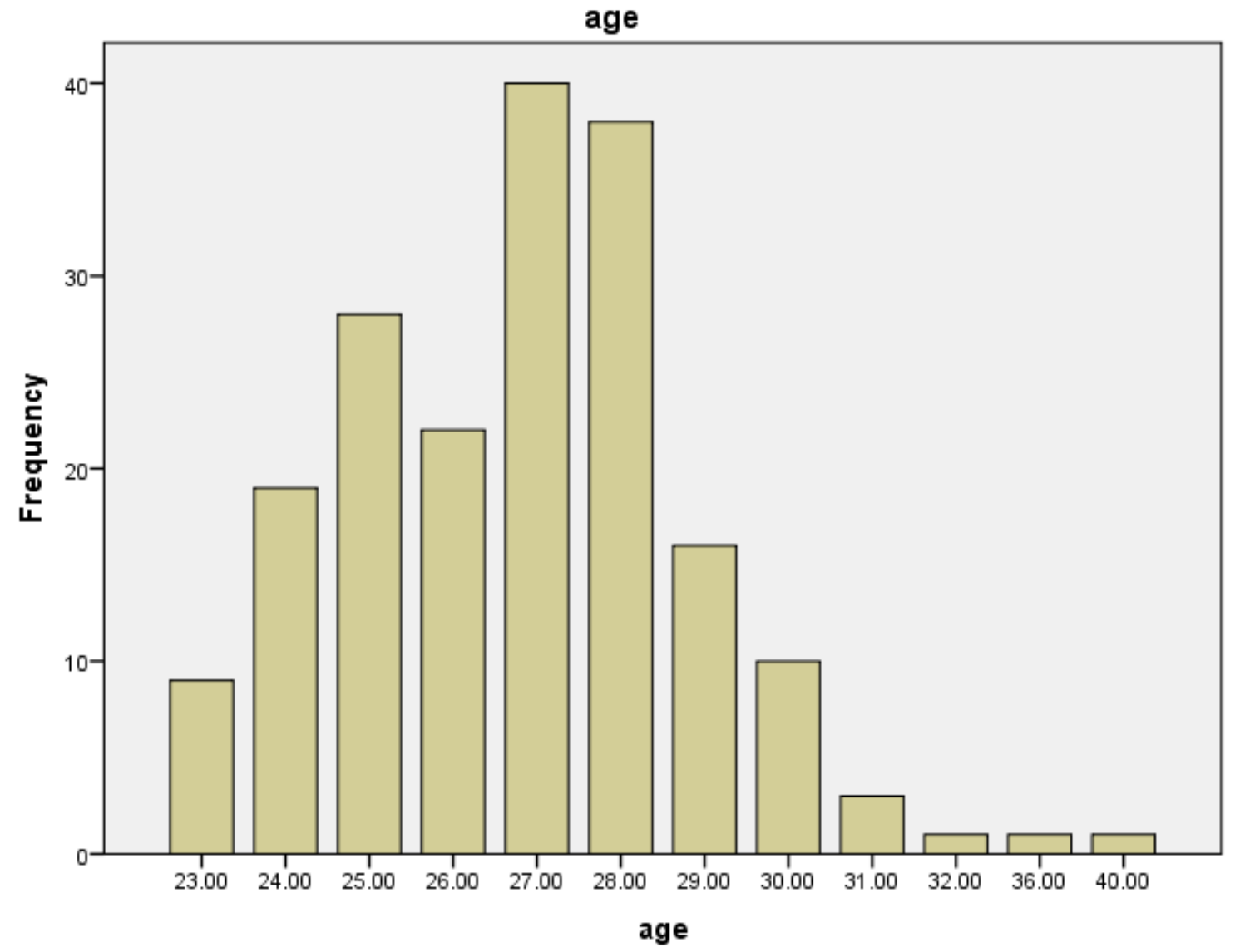

Figure 1. Age of respondents in years.

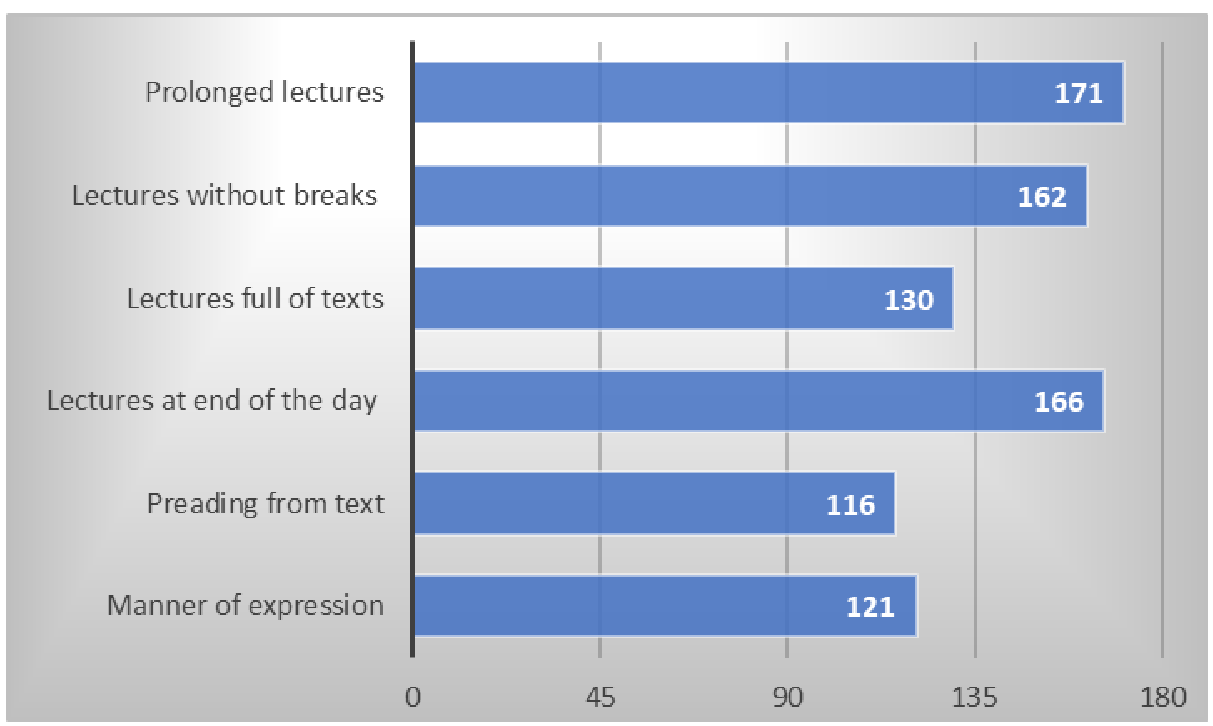

Figure 2. Number that agreed with the different options 